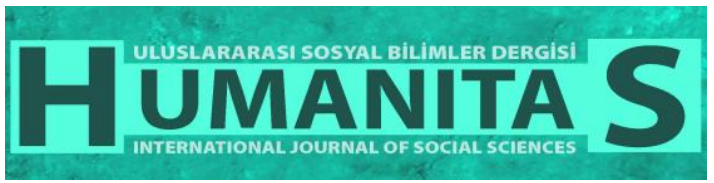

Humanitas, 2018; 6 (12): 204-214

ISSN: 2645-8837

http://dergipark.gov.tr/humanitas

\title{
İHSAN OKTAY ANAR'DA POSTMODERN BİR TERCİH OLARAK DİLIN, YAZIM KURALLARINA AYKIRI KULLANIMI
}

\begin{abstract}
Mehmet $\mathbf{O Z Z}^{1}$
Özet

Modernizm sonrası veya ötesi anlamlarına gelen postmodernizm, modernizmin ortaya koyduğu değerlerin artık işlevlerini yitirdiği iddiasındadır. Aydınlanma ve modernizmin daha iyi, daha gelişmiş huzurlu bir dünya; ekonomi ve sosyal hayattaki yeni gelişmelerle daha mutlu olacak insan vaatlerinin gerçekleşmediğini; bu iyimser amaç ve beklentilerin sömürüye, savaşlara, yıkıcı birçok şeye çare oluşturmadığı öne süren postmodernizm; çoğu yönden modernizme karşıt bir düşünceye sahiptir. $\mathrm{Bu}$ yüzden de postmodernizm; modernizmin amaç, hiyerarşi, merkezilik, sınır, belirlenmişlik, belli bir tür, tasarım, gösterilen gibi unsurlarının karşısına rastlantı, oyun, çoğulculuk, melezlik, anarşi, gösteren, metinlerarasılık gibi modernist unsurlardan farklı veya bunlara karşıt unsurlarla çıkmaktadır. Postmodernizmin bu tavrını mimaride, resimde, edebiyatta ve diğer alanlarda da görmek mümkündür. Edebiyattaki bu tutum eserlerin diline de yansıdığı için, dildeki birçok söz dizimi ve dilbilgisi kuralının da göz ardı edilmesine sebep olmaktadır. Özellikle pastiş, parodi, kolaj gibi daha çok postmodern edebiyat ile anılan tekniklerin kullanıldığı bölümlerde bu daha fazla görülür. Bizim de bu makaledeki amacımız öncelikle postmodernizmin modernizme olan aykırı tutumunu ortaya koymak, daha sonra bu tutumun edebiyata ve edebi dile yansımalarını göstermek ve en sonunda da bunu İhsan Oktay Anar'ın Efrasiyab'ın Hikayeleri, Amat ve Yedinci Gün adlı eserlerinden faydalanarak örneklerle ortaya koymaktır. Bu örneklerin doğru veya yanlış (aykırı) yazımına dair tespitlerde Türk Dil Kurumu Yazım Kılavuzu esas alınacaktır.
\end{abstract}

Anahtar Sözcükler: postmodernizm, modernizm, dil, Türkçe yazım, İhsan Oktay Anar

\footnotetext{
${ }^{1}$ Yüksek Lisans Mezunu, Osmaniye Korkut Üniversitesi, Fen Edebiyat Fakültesi, Türk Dili ve Edebiyatı Bölümü. mehmetozozz@ hotmail.com
} 
Öz, M. (2018). İhsan Oktay Anar'da Postmodern Bir Tercih Olarak Dilin, Yazım Kurallarına Aykırı Kullanımı. Humanitas, 6(12), 204-214

\title{
UNGRAMMATICAL USE OF LANGUAGE BY IHSAN OKTAY ANAR AS A POSTMODERN PREFERENCE
}

\begin{abstract}
Postmodernism, meaning post or beyond modernism, claims that the values put forth by modernism have now lost its functions, suggesting also that promises of a better, more developed peaceful world and of humankind made happier with new developments in the economic and social life have not came true, that those optimistic goals and expectations have not constituted a remedy for exploitation, wars, many other destructive things, and that postmodernism is mostly in direct contradiction to modernism. Modernist elements such as purpose, hierarchy, centrality, border, determinism, certain kind, design, displayed are confronted by different or contrary elements of postmodernism such as coincidence, play, pluralism, hybridity, anarchy, exhibitant, intertextuality. It is possible to observe this attitude of postmodernism in architecture, painting, literature and other fields. Because this attitude in literature reflects upon the language of the works, it results in the ruling out of many syntax and grammar rules of the language. This can be observed more frequently in sections that techniques associated with postmodern literature such as pastiche, parody, collage are used. Our aim in this article is to first reveal the contradictory attitude of postmodernism against modernism, then to show its reflection on literature and literary language and finally, to present it by utilizing the works of İhsan Oktay Anar, namely Stories of Efrasiyab, Amat and Seventh Day. The Turkish Language Association Spelling Dictionary will be the basis for determining correct or incorrect (contradictory) spelling of these examples.
\end{abstract}

Keywords: postmodernism, modernism, language, Turkish writing, İhsan Oktay Anar.

\section{Giriş}

Lacan, Derrida, Foucault, Barthes, Lyotard, Baudrillard gibi önemli düşünürlerin etkisiyle postmodernizm şüphesiz y1llar geçtikçe hemen her alanda etkisi hissedilen bir düşünce akımıdır. Bu düşünce akımı modernizme ait birçok özelliğe karşı çıkar. Modernizm Özellikle aydınlanma ve sanayileşme ile birlikte bir yeryüzü cenneti vaat etmişti. Çünkü “modernlik tasarısı XVIII. yüzyılda yaşamış aydınlanma filozoflarının nesnel bir bilim, genel geçer bir ahlak, evrensel bir hukuk, özerk bir sanat geliştirmeye dönük gayretleriyle" (Sarup, 2017, s. 204) oluşmuştu. Haliyle de aydınlanma filozoflarıyla geliştirilen bilim, evrensel hukuk, akıl vs. her şeyi çözümleyecek, insan daha müreffeh bir hayata kavuşacak, yeryüzündeki problemler büyük oranda çözülecekti. Gelişen bilim ve teknoloji insanlığa daha 
aydınlık bir dünya getirecekti. Postmodern düşüncenin modern düşünceye karşı duruşunun önemli bir gerekçesi bütün bunların hedeflenen dünya yerine bunun tam tersi bir dünya getirmiş olduğu savıydı. Gerçekten de modernizme bakıldığı zaman onun yukarıda anlatılan iddialara ve unsurlara sahip olduğu görülmektedir. Yıldız Ecevit'in de belirttiği gibi modernizm her bilgiyi sistematize etmek isteyen, kuralc1, aklın güdümündeki Batı düşüncesinin doruğuydu (Ecevit, 2016, s. 41). Bundan yola çıkıldığında modernizmin kuralcı, sistematik, aklı ön plana çıkaran; sınıflandırmayı, çizgilerde netliği ve zıtlıkları önemseyen bir yapıya sahip olduğu görülür. Zaten David Harvey'in Ihab Hassan'ın Paracriticism adlı eserinden aldığı bir tabloda gördüğümüz modernist unsurların bir kısmı şunlardır: amaç, tasarım, hiyerarşi, bitmiş yapıt, tür/sınır, merkezlenme, hakimiyet, belirlenmişlik, gösterilen (Harvey, 2014, s. 59). Bütün bunlar göz önüne alındığında bu, adeta "programlanmış kusursuzluk" (Baudrillard, 2016, s. 60) gibidir.

Postmodernizm ise bu programlanmış kusursuzluğun insanlığa kusursuz bir hayat getirmediğini belirtir. Çünkü bu kusursuz programın iyimser vaatleri gerçekleşmedi. Örneğin yeryüzünde sömürü, ayrımcılık, sınıflandırma ortadan kalkmadı. İnsanın yalnızlaşması, yabancılaşması, bir tüketim nesnesine indirgenmesi gibi durumlar hiç de iç açıcı sonuçlar değildi. Modernizm yirminci yüzyılda, milyonla insanın ölümüne ve büyük yıkımlara sebep olan iki dünya savaşıyla, özellikle Hiroşima-Nagazaki örneklikleriyle, günden güne artan, gelişen nükleer ve kimyasal silahlarıyla vaat ettiği cenneti gerçekleştirmenin uzağına düştü. Bütün bunlar da modernizme karşı seslerin yükseltilmesini sağladı. Bu seslerden biri de postmodernizmdi.

Yukarıda bazı isimleri de dillendirilen postmodern düşünürler modernist unsurların karşısına oyun, rastlantı, çoğulculuk, karnaval, anarşi, belirsizlik, melezlik, merkezsizlik, yersiz yurtsuzluk, ironi, kolaj gibi unsurları çıkararak modernizmi tersyüz etme; modernizmin maskesini düşürme amacı güttüler. Çünkü postmodernizm, hemen her alanda değişmez kalıpları ve yargıları gözeten yaklaşımları reddeden bir tavır sergiliyordu. Modernizmin standartlarını yıkmayı amaç ediniyordu. Bu anlayış "İnsanların pijamalarının üzerine çizin resimlerinizi" (Eagleton, 2010, s. 461) diyebiliyordu. Tuval yerine pijamaların üzerine resim çağrısı farklı ve aykırı bir çağrıydı. Yine Peter V. Zima "tüm değerleri tersine çeviremez miyiz? Belki de iyi, kötünün kendisidir, olamaz mı?” (Zima, 2006, s. 248) diyordu. Şüphesiz ki bu; belirliliği kesinliği ve netliği önemseyen modernizmin kendi geleneksel anlayışının dışında bir anlayıştı. Pijama üzerine resim çizme isteği grotesk bir tavırdı. Zaten postmodernizm, bir araya gelmesi düşünülmeyen unsurları grotesk bir tavırla bir araya 
getirerek modernizme aykırı bir tutum sergilemekteydi. Bu, modernizmdeki "geleneksel anlayışın tümüyle dışında bir kulvara geçiş” (Ecevit, 2016, s. 62) yapan bir tavırdı. Postmodernizm bu yolla geleneksel anlayışa oldukça aykırı bir yol ortaya koyuyordu. Modernizmin kalıcılık, kesinlik, bütünlük, süreklilik, düzen gibi unsurlarının yerini "gelip geçicilik, parçalanma, süreksizlik ve kargaşa" (Harvey, 2014, s. 60) alıyordu. Bir araya gelmesi mümkün olamayan her unsur burada bir araya gelebiliyordu. Kot pantolon ve başörtüsü, türkü ve bar, Anadolu ve rock, zemzem ve tower gibi unsurlar artık rahatlıkla yan yana kullanılabiliyordu. Çünkü "Yeni düşüncede tüm ölçütler hiçbir önem sırası olmaksızın yan yana" (Ecevit, 2016, s. 62) sergilenmekteydi. Böylece postmodernizm bir karnavalı, bir kokteyli andırıyordu. Nice karşııtlı̆̆ın yana yana, iç içe yaşadığı melez, çoğulcu bir oyun gibi.

\section{Postmodern Edebiyat ve Dil}

Postmodernizmin yukarıda anlatılan tutumu şüphesiz ki edebiyatı da etkilemiştir. Haliyle postmodern edebiyatta da modern edebiyata aykırı tutumlar görülmektedir. Örneğin postmodern eserlerde kasıtlı amaçlanmış bir derinlik yokluğu göze çarpmaktadır. Çünkü amaç herhangi bir konuda derine inmek, o konuyu derinlemesine ortaya koymak değildir. "Vurgunun içerikten biçime ya da biçeme kayışı, gerçekliğin imajlara dönüşümü" (Sarup, 2017, s. 188) postmodern eserlerin bir başka özelliğidir. Bu eserlerde tek bir amaç, bakış açısı veya üslup yerine çoğul, karmaşık bir yapı ön plana çıkmaktadır. Bu grotesk yapıda birçok biçimin birlikteliği göze çarpıyor. Anlam üretimi artık yazar/metin/kahramandan okura kayıyor. Metinde anlam, okuyucu da metnin içine çekilerek metin ve okuyucu tarafindan birlikte inşa edilmektedir. "Keskin tonların flulaştı̆̆ı" (Koçakoğlu, 2012, s. 15) postmodern metinler, başka metinlerden izler taşıyan bir ağı andırmaktadır. Her metin başka bir metne göndermede bulunduğu için metinde tek bir anlamın ve yorumun varlı̆̆ kabul edilmemektedir. Birçok postmodern romanda bu görülmektedir. Genellikle bir mesaj kaygısı da taşımayan bu romanlarda özne-nesne, gerçek-kurmaca, hayali dünya-gerçek dünya gibi karşıtlıklar iç içe, yan yana sergileniyor. Genellikle kopuk ve parçalı bir olay örgüsünün sergilendiği bu romanlarda modern romanlardaki kronolojik, düzenli bir zaman kavramı görülmemektedir. Çünkü yazar daldan dala atlayarak, sürekli geçmişten geleceğe, gelecekten geçmişe sıçramalar yaparak kronolojik zaman anlayışını bilinçli bir şekilde kırmaya çalışıyor. Postmodern yazarlar benzer tavırları mekan ve diğer unsurlarda da sergilemektedirler. Örneğin bir veya birkaç ana kahramanın merkezde yer aldığı bir şahıs kadrosu pek görülmemektedir. Metinlerarasılık yolu ile birçok metin, üslup, biçim bir araya getirilerek bütün bunlar karmaşık bir şekilde sergilenmektedir. Zaten postmodern yazarlara göre 
yeryüzünde her şey söylendiğine göre, önemli olan yeni şeyler söylemek değil, söylenenleri yeni bir yapıda bir araya getirmektir. Bir çeşit kokteyl veya Bahtin'in ifadesiyle "karnaval" oluşturmak. Örneğin İhsan Oktay Anar, Yedinci Gün adlı eserinde Tevfik Fikret'in yağmur şiirini ironik bir paragrafin içinde şu şekilde kullanmıştır: "Şairin dediği gibi tıpkı inci yahut tıpatıp jale misâli, muttarid, muhteriz ve tâbnâk damlalar, arabanın ratıp camında taptapa ile tıpırdıyordu. Aşağı inen sürücü kapıyı açıp (...) hürmetle yerlere kadar eğildi. Yaratılıştan kılbaz ve piyazcı olan sürücü o güne kadar, hürmetle eğilmenin çok faydasını görmüştü” (Anar, 2016, s. 28). Yine aynı eserde Mevlid'in "Ol Rebi-ûl evvel âyın nicesi” dizesi ile başlayan bölümünün, kimi sözcükleri değiştirilerek, böyle ironik bir yapının bir parçası kılındığı görülmektedir. "Ânesi anda niler kördü niler / Didi kördüm ol habibin ânesi / Bi âcep nûr kim küneş birvânesi” (Anar, 2016, s. 124)

Postmodernizmin edebi eserlerdeki bu aykırı tavrı eserlerin dilinde de görülmektedir. Postmodernistlerin bir kısmı tarafından dil egemen sınıfın bir unsuru olarak görüldüğü için dilin var olan yapısı da bilinçli olarak bozulmaya çalışılmaktadır. Postmodernistler "Sanat, geleneksel formu ve anlamı ezip geçecektir; çünkü söz dizim ve dilbilgisi yasaları, siyasi yasalara eşdeğerdir" (Eagleton, 2010, s. 461) anlayışı ile alışılmış söz dizim ve dilbilgisi kurallarına aykırı bir tutum içine girmektedirler. Elbette postmodernizmde dil önemlidir. "Postmodern roman için hiçbir unsur dil kadar önemli değildir. Hatta postmodern metinler dili sergileyebilmek, dili kullanabilmek, dille bir arada olabilmek amaciyla oluşturulur, demek yanlış olmayacaktır" (Somuncuoğlu, 2014, s. 973-987). Çünkü postmodern eserlerde dilbilim unsurlarından amac1/mesajı karşılayan gösterilen değil bu amacı/mesajı işaret eden gösteren (ses, şekil, resim vb.) ön plana çıkar. Bu yüzden dilin, ifade edeceği mesaj değil, bu dilin unsurlarının bir araya getirildiği yapı daha önemlidir. Hatta "postmodernistlere göre dil dışında hiçbir şey yoktur" (Murphy, 2000, s. 53) ama bu dil alışılmış bir dil değildir. Bu dil, alışıımış dilin dışında çokça aykırı unsuru barındıran bir dildir. Burada dildeki net çizgiler ortadan kaldırılarak dilin "belirsiz bir fenomene indirgenmesi" (Ellul, 2012, s. 218) söz konusudur. Böylece çoğu zaman hiçbir kuralı tanımayan, kuralları tahrip edilen bir dil ortaya çıkmaktadır. Burada artık "her türlü aktörel erimi yıkan bir dil söz konusudur" (Barthes, 2016, s. 44). Bu, özellikle de dilde yapılır. Postmodern eserlerde dil oyunlarına da çokça başvurulur. Sonuçta "postmodernistlerin kural tanımazlık, belirsizlik, tutarsızlık, mekanik olanın dışına çıkma vs. gibi pek çoğu göreceli çağrışımlar uyandıran yaklaşımlarında hep dil mekanizması karşımıza çıkar" (Emre, 2006, s. 103). 
Postmodern dil bilinçli bir tavrın ürünüdür. Postmodern yazar, modern yazarın sistematik, genel geçer unsurlara uygun düzenli dilini bilinçli bir şekilde bozmaya çalışır. Yazar "bilinçli olarak eğlendirici/sürükleyici görünümlü öğelerle donatır metnini." (Ecevit, 2016, s. 74). Burada asıl amaç modernizmin diğer unsurlarında olduğu gibi dil unsurunda da modernizme aykırı bir tutum sergilemek, modernizmin kurallarını yıkmaktır. Bu yüzden de yazarlar "geleneksel, akademik söylem tarzlarını reddederler; cüretkar ve kışkırtıcı hitap biçimleri” (Rosenau, 1992, s. 28) kullanırlar. Metni bir kokteyl, karnaval havasına büründürürler. Dilde bunu, kimi zaman alaylı kimi zaman da ciddi bir şekilde pastiş ve parodi gibi unsurları kullanarak veya kolaj gibi her şeyi gelişigüzel bir araya getiren bir unsuru kullanarak yaparlar. $\mathrm{Bu}$ da dilde karmaşık, birçok değişik ve aykırı unsuru barındıran, tanımlanmış ölçütlerin dışında çoğulcu bir dil ortaya çıkarır. Farklı, aykırı nice unsurun bir araya geldiği bu çoğulcu yapı, dilin kurallarını tanımayan farklı bir dil ortaya çıkarır. Böylece "modernin sistematik hale getirip ihtisaslaştırdığı dil, dilbilgisi kurallarına uyulmayan, alışılmış konvansiyonların dışında kullanılan daha anarşik bir zemine çekilmiş olur.” (Emre, 2006, s. 111).

Diğer dillerde olduğu gibi bu aykırı kullanım Türkçede de Türkçenin söz dizimi, dilbilgisi ve imla kurallarını kimi zaman tanımayan, bu kuralları bilinçli olarak bozan bir tavrın ortaya çıkmasına sebep olmaktadır. Bu aykırı tavır, yazım kılavuzu (Yazım Kılavuzu, 2006) esas alınarak, İhsan Oktay Anar'ın üç eserinden örneklerle ortaya konmaya çalışılacaktır.

\section{İhsan Oktay Anar Örnekliğinde Postmodern Dil}

İhsan Oktay Anar'ın eserlerinde postmodern edebiyatın hemen hemen bütün özellikleri görülmektedir. Bu özelliklerden biri de bilinçli bir tercih olarak yazarın dilde sergilediği aykırı tutumdur. Özellikle ironik anlatımın yoğun olduğu pastij ve parodilerde bu tutum, birçok örnekte görülmektedir. Bunun bilinçli bir tercih olduğu, yazım kurallarına aykırı bir şekilde yazılan sözcüklerin kullanıldığı bağlamdan anlaşılmaktadır. Bütün bunlar postmodernizme uygun bir tavrın göstergeleridir. Yukarıda da değinildiği gibi postmodern eserlerde dil, kimi zaman geleneksel yazım kurallarına, söz dizimine aykırı bir şekilde kullanılmaktadır. İhsan Oktay'ın eserlerinde de Türkçenin yazım kurallarına aykırı epey örneğe rastlanmaktadır. Bütün bu örnekler İhsan Oktay Anar'ın eserlerinde bilinçli bir tercihin ürünleri olarak karşımıza çıkmaktadır. Türkçenin yazım kurallarına olan bu kimi aykırılıkların aşağıdaki şekillerde gerçekleştiği görülmektedir. 


\section{Uzatma İşareti Kullanılmayan Sözcüklerde Uzatma İşareti Kullanma}

İhsan Oktay Anar'ın eserlerinde çokça görülen yazım kurallarına aykırı kullanımlardan birisi, artık uzatma işareti kullanılmayan sözcüklerde bile onun, bu işareti bilinçli bir tercih olarak kullanmaya devam etmesidir. Bunun bilinçli bir tercih olduğu, bu sözcüklerin kullanıldı̆̆ı ironik bağlamdan çıkarılabilir. Örneğin "Zavallı ise âkibetini bile bile 'Döv beni adam olayım!' ibaresini yüksek sesle telaffuz eder”' (Efrasiyab'ın Hikayeleri, 2004, s. 20) cümlesindeki "âkibet” sözcüğünde bu görülmektedir. Yine "nöbetçi muallimlerden kurulu inzibat ekipleri yatakhanelere ve koğuşlara âni baskınlarla kâbus gibi girerler.” (Efrasiyab’ın Hikayeleri, 2004, s. 21) cümlesindeki “âni” ve "kâbus" sözcüklerinde de böylesi bir kullanım söz konusudur. "Efendimiz onun, temizliğinden mesul olduğu ayakyolunu bizzât kendi hâcetini de def etmek için ara sıra sûistimâl ettiğinden” (Yedinci Gün, 2016, s. 9) cümlesindeki "bizzât", "hâcet", "sûistimâl” sözcüklerinde de aynı tavır göze çarpmaktadır. Oysaki bütün bu yazımlar Türkçe yazım kurallarına aykırı kullanımlardır. Türkçe yazım kurallarına baktığımızda (Yazım Kılavuzu, 2006) bu sözcüklerin yazımında uzatma işareti kullanılmamaktadır. Bu tarz kullanıma Yedinci Gün romanındaki esnâda (s. 9); devâsâ, lânet, binâ (s. 10); fukârası, meşgûl, kitâba (s. 11); zifirî (s. 15) sözcüklerinde de rastlanmaktadır. Aynı kullanım Efrasiyab'ın Hikayeleri'ndeki lâkabı (s. 23), yâdettiklerini (s. 24) sözcüklerinde de vardır. Benzer kullanımlara İhsan Oktay Anar'ın eserlerinde çokça rastlanmaktadır.

\section{Küçük ve Büyük Harf Kullanımında Aykırı Tutumlar}

İhsan Oktay Anar'in eserlerinde bilinçli bir tercih olarak küçük ve büyük harflerin yanlış olarak kullanıldığı örnekler de görülmektedir. Yukarıda da değinildiği gibi bu da postmodern dile uygun bir tavırdır. Örneğin "kendisine fazlaca ağırlık vermiş olsa gerek ki Ulu Hakanımız havagazı lambasını kapattı" (Yedinci Gün, 2016, s. 9) cümlesindeki "Ulu Hakanımız" ifadesinde Türkçe yazım kurallarına aykırı olarak büyük harfler kullanılmıştır. $\mathrm{Bu}$ cümlenin kullanıldığı sayfadaki bağlama bakıldığında amacın tariz yoluyla hükümdarla alay etmek olduğu görülmektedir. Yine Yedinci Gün romanındaki "sonra maktûlü Cennet'e tez vakitte yollamak isteyen" (s. 18) cümlesinde geçen "Cennet'e" sözcügünde de aynı kullanım göze çarpmaktadır. Efrasiyab'ın Hikayeleri’nde cümlenin başında kullanılmadığ halde "Ölüm'e" (s. 15) sözcüğünde de aynı kullanım vardır. "Kaptan Efendimizden, yani Diyavol Paşa'dan" (Amat, 2006, s. 30) cümlesindeki "Efendimizden” sözcügünde de bunun 
başka bir örneği görülmektedir. Her üç eserde de bu aykırı kullanımların başka örneklerine de rastlanmaktadır. Bütün bu örnekler bunun bilinçli bir tercih olduğunu göstermektedir.

\section{Sözcüklerin Birleşik veya Ayrı Yazımlarında Aykırılık}

Postmodern eserlerde gördüğ̈̈müz aykırı bir kullanım da ayrı yazılması gereken sözcüklerin birleşik, birleşik yazılması gereken sözcüklerin bilinçli olarak ayrı yazılmasıdır. Burada da amacın ironik olduğu, bağlamdan anlaşılmaktadır. Bu kullanıma İhsan Oktay Anar'ın eserlerinde çokça rastlanmaktadır. "Bak burada, karazindanağusu elde edilen tilkifenerinin... sığırgelinotunun demlenip... sarıkâzımkanı” (Amat, 2006, s. 188) cümlesinde birleşik yazılmış olan sözcüklerde yazım kurallarına aykırı olan bu kullanım görülmektedir. Yazım kurallarına aykırı olan bu kullanım, Efrasiyab'ın Hikayeleri'ndeki geceyarısı (s.15), yâdettiklerini, gözkapaklarını (s. 24), düşgücünün (s. 31), ölümdöşeği (s. 103), terkedilmiş (s. 107), hamamböceği (s. 156) sözcüklerinde de göze çarpmaktadır. Yine Yedinci Gün'deki “güçbelâ” (s.12), "Elmacıkkemikli” (s. 50) sözcükleri de bu aykırı kullanıma birer örnektir.

\section{Arapça ve Farsça Tamlama Kurallarının Kullanımı}

Yazarın ironik bir anlatım oluşturmak için ortaya koyduğu tamlamalarda sık sık Arapça veya Farsça tamlama kurallarının kullanıldığı görülüyor. Bu tamlamaların kullanıldığı bağlam göz önüne alındığında bunun da bilinçli bir aykırı tercih olduğu ortadadır. Örneğin “... felaket ciğerine işleyerek onu azılı bir kumarbaz yapmıştı. Ne var ki Paşaoğlu, laboratuvarda ilmi bir tecrübenin neticesini beklerken kapıldığı cezbeye, elektrikîye-i sâkine muhassalasının iki topuzu arasında... üzerinde çalıştığı harümüntakilî supabın cereyân-1 elektrikîyeyi” (Yedinci Gün, 2016, s. 24) cümlelerindeki "elektrikîye-i sâkine” , "cereyân-1 elektrikîyeyi" tamlamaları bunu örnekliyor. Yine aynı eserdeki "Şu gâita-yı muazzamaya bir bakın, sanki 'merd süprem'.” (s. 216) cümlesinde de aynı kullanım var. Amat romanındaki "tabir-i caizse" (s. 92) ifadesi de benzer şekilde Türkçenin yazım kurallarına aykırı bir kullanımdır.

\section{Sözcüklerin Yanlış Yazımı}

İhsan Oktay’ın eserlerinde görülen bir yazım aykırılığı da sözcüklerin bilinçli olarak yanlış yazılmasıdır. Özellikle ironik anlatımın yoğunlaştığı, pastiş ve parodilerin kullanıldığı bölümlerde bu sözcüklere daha çok rastlanıyor. Yedinci Gün romanında "topçu kışlasının siluetini örttüğü” (s. 13)cümlesinde silüet sözcügünün "siluet” şeklinde yazılmış olması buna 
örnektir. Aynı romanın "Yaradılıştan kılbaz ve piyazcı olan sürücü” (s. 28) cümlesindeki "Yaradılıştan" sözcügünde de böyle bir örnek görülmektedir. Yine adı geçen romanda geçen "Havana sigarlarından tüten duman içinde az buçuk sönse de bu ortamı" cümlesindeki “sigarlarından” sözcüğü de bu kullanımı örneklemektedir. Bu eserdeki “ahıretini” (s. 17) sözcüğü de bilinçli olarak yanlış yazılmıştır. Efrasiyab'ın Hikayeleri'nde de benzer kullanımlar görülüyor. Örneğin "tabiyatiyle” (s. 176) sözcüğü böylesi bir kullanımdır. Amat romanında kullanılan "zından" (s.11), "Aristâtalis" (s. 28), "Fisagor" (s. 30), "Küthüdânıza" (s. 39), "Kulhuvallu” (s. 54), "züttüre” (s. 188), "1zbandut" (s. 220) sözcükleri de ironik bir anlatım sağlamak için bilinçli olarak yanlış yazılmıştır.

\section{Uydurulmuş Sözcüklerin Kullanılması}

İhsan Oktay Anar'ın eserlerinde görülen diğer aykırı bir tutum da uydurulmuş kimi sözcüklerin kullanımıdır. Bu, postmodern eserlerde yer yer sergilenen bir tavırdır. İhsan Oktay Anar bunu bilinçli bir şekilde yapmaktadır. Buna örnek olarak Yedinci Gün romanındaki şu metin örnek gösterilebilir:

“Şu

Ezlâmuteahhem

Serbaklağanc1

Özbelindirikimsi

Beryortumgantırak

Su" (s. 206)

Yukarıdaki metinde birçok kelimenin uydurulmuş olduğu görülmektedir. Örneğin “özbelindirikimsi” sözcüğü böylesi bir kulanımdır. Bu örneklerin kullanıldığı sayfalara tamamen ironik bir anlatımın hakim olduğu gözlenmektedir. Örneğin yukarıdaki şiir, hiç de şiire benzemediği halde, Yedinci Gün romanının bir kişisi olan, kendisini büyük bir şair zanneden İdris Amil Zula'ya aittir. Yazar burada şair geçinenleri alaya almak amaciyla bunu kullanmıştır. Buna benzer kullanımlar yazarın hemen bütün eserlerinde görülmektedir. Bunun da postmodern tavra uygun bilinçli bir tercih olduğu söylenebilir.

\section{Sonuç}

Postmodernizm, modernizme bir tepki olarak ortaya çıkan; modernizmin amaç, hiyerarşi, derinlik, kesinlik, tasarım vb. unsurlarının karşısına oyun, anarşi, çoğulculuk, 
melezlik, belirsizlik gibi unsurları koyan bir düşüncedir. Bu yönüyle modernizmden farklı, ona aykırı bir tutumun içindedir. Postmodernizmin bu tavrı mimaride, sinemada, resimde, müzikte ve diğer alanlarda göze çarpmaktadır. Bu tavrın edebiyata da yansıdığı postmodern eserlere bakıldığında rahatlıkla görülmektedir. Örneğin postmodern eserlerde sergilenen farklı bir zaman ve mekan algısı, kopuk ve parçalı olay örgüsü, kahraman merkezli olmayan şahıs kadrosu, dil oyunları, grotesk tapı vb. özellikler bunu göstermektedir. Postmodernizmin bu aykırı tutumu edebi dilde de görülmektedir. Çünkü kimi postmodern düşünürler dili de toplumu denetim mekanizmalarından biri olarak gördüklerinden kuralları ve sınırları belli olan bu dile karşı çıkmaktadırlar. Bu yüzden de postmodern anlayış ile yazan birçok yazar farklı, aykırı bir dil kullanımını benimsemektedir. Bu dil haliyle de çoğu zaman modernist eserlerde sergilenen dilden farklı bir dildir. İhsan Oktay Anar da bu çizgideki postmodern yazarlardan biridir. Onun eserlerinde de geleneksel dilin yerleşik ve belli yazım kuralarına aykırı kullanımlar çokça görülmektedir. Yazar, kimi zaman Türkçe yazım kuralarına aykırı tamlamaları (özellikle Farsça ve Arapça tamlama kurallarına uygun), kimi zaman uydurulmuş kelimeleri kullanarak, kimi zaman da sözcükleri yanlış yazarak bu tutumunu ortaya koymaktadır. Ayrıca yazarın, büyük harf-küçük harf kullanımını, sözcüklerin birleşik ve ayrı yazımlarına ait kuralları da göz ardı ettiği görülmektedir. Bu da Türkçenin yazım kurallarına aykırı bir tutum ortaya çıkarmaktadır. Bu makalede de bu aykırı, farklı tutum postmodern bir çizgide yazmaya devam eden yazarlardan İhsan Oktay Anar'ın eserlerinden örneklerle ortaya konmaya çalışıldı. 
Öz, M. (2018). İhsan Oktay Anar'da Postmodern Bir Tercih Olarak Dilin, Yazım Kurallarına Aykırı Kullanımı. Humanitas, 6(12), 204-214

\section{Kaynakça}

Anar, İ. O. (2004). Efrasiyab'ın Hikayeleri. İstanbul: İletişim Yay.

Anar, İ. O. (2006). Amat. İstanbul: İletişim Yay.

Anar, İ. O. (2016). Yedinci Gün. İstanbul: İletişim Yay.

Barthes, R. (2016). Yazının Sıfır Derecesi. (T. Yücel, Çev.) İstanbul: YKY.

Baudrillard, J. (2016). Simülakrlar ve Simülasyon. (O. Adanır, Çev.) Ankara: Doğubatı Yay.

Eagleton, T. (2010). Estetiğin İdeolojisi. (B. Kıroğlu, Çev.) İstanbul: Doruk Yay.

Ecevit, Y. (2016). Türk Romanında Postmodernist Açılımlar. İstanbul: İletişim Yay.

Ellul, J. (2012). Sözün Düşüşü. (H. Arslan, Çev.) İstanbul: Paradigma Yay.

Emre, İ. (2006). Postmodernizm ve Edebiyat. Ankara: An1 Yay.

Harvey, D. (2014). Postmodernliğin Durumu. (S. Savran, Çev.) İstanbul: Metis Yay.

Koçakoğlu, B. (2012). Anlamsızlığın Anlamı Postmodernizm. Ankara: Hece Yay.

Murphy, J. (2000). Postmodern Sosyal Analiz ve Postmodern Eleştiri. (H. Arslan, Çev. İstanbul: Paradigma Yay.

Özot, G. S. (2014, İlkbahar). Postmodern Roman: Kurgu, Dil ve Kişiler Kadrosu. Turkish Studies, 973-987.

Rosenau, P. M. (1992). Postmodernizm ve Toplum Bilimleri. (T. Birkan, Çev.) İstanbul: Ark Yay.

Sarup. M. (2017). Postyapısalcılık ve Postmodernizm. (A. Güçlü, Çev.) Ankara: Pharmakon Yay.

Türk Dil Kurumu. (2006). Yazım Klavuzu. Ankara: Türk Dil Kurumu Yay.

Zima, P. V. (2006). Modern Edebiyat Teorilerinin Felsefesi. (M. Özsarı, Çev.) İstanbul: Hece Yay. 